\title{
Effects on Female University Students' Physical Health
}

\author{
Yu Dong \\ Department of Physical Education, Beijing Institute of Petrochemical Technology, Beijing, CHINA \\ Xi Lu \\ Department of Public Physical and Art Education, Zhejiang University, Hangzhou, Zhejiang, CHINA
}

Guo-wei Xu

The China National Children Center, Beijing, CHINA

Received 27 May 2017 • Revised 24 August 2017 - Accepted 1 October 2017

\begin{abstract}
Objective: With the development of economy, our living level is being improved, and we pay more and more attention to physical health, whereas a well-built and shapely body and good temperament is also an inevitable requirement of social development. With regard to this, implementing aerobics teaching in universities could adapt to the demands of social development. Research methods: In this paper, literature review, experimental comparison, mathematical statistics were applied to mainly explore the effects of aerobics on female university students' physical health. Research results show that aerobics teaching were mainly divided into physical training and dance training, which were characterized by elegant, artistic, comprehensive, targeted, rich movement contents and simple movement. Aerobics teaching could correct undesirable female university students' body shape, contribute to their well shape building, reduce excessive body fat and improve body functions effectively, enhance their heart and lung functions and cardiovascular system and then further promote their physical health level.
\end{abstract}

Keywords: aerobics teaching, female university students, physical health, educational function

\section{INTRODUCTION}

Aerobics teaching is a kind of comprehensive art that integrates fitness, bodybuilding exercises, music and dance. The event has become well received by people especially for women with its increasing popularity. It is able to exercise one's body and enhance one's physique. As social living standards improve, there come two kinds of unhomely body shapes-too fat or too thin. Aerobics is a kind of aerobic exercise that contributes to weight loss and physique enhancement and beautiful body shaping. Female University students are in the period of perfecting and improving of physical and psychological development in university, anyone of them is longing for a good figure and healthy body, and they greatly care for personal body shape and beautiful figure (Li et al., 2017). The aerobics is a kind of body exercise events based on aerobic energy supply and characterized by health, strength and beauty. For female university students, they are in the stage of unformed body; the implementation of aerobics teaching plays an important role in correcting their body shape and improving their body functions. Moreover, the beautiful body movement in aerobics could be used to facilitate female university students' physical and formal beauty (Chen \& Zhang, 2016). On this basis, we gradually cultivate their pursuit of art to improve their comprehensive ability

(C) Authors. Terms and conditions of Creative Commons Attribution 4.0 International (CC BY 4.0) apply. Correspondence: Yu Dong, Department of Physical Education, Beijing Institute of Petrochemical Technology, 102618, Beijing, China.

\. Yudong1982@163.com 


\section{Contribution of this paper to the literature}

- Aerobics teaching can correct the unhealthy body shape of female college students and shape the beautiful body of female students, so as to improve the health of female students.

- Aerobics teaching and training can reduce the body fat of female college students.

- After the training of aerobics, the girl can prevent the occurrence of obesity can also improve the body's immunity, promote the blood circulation, ensure the health.

and accomplishment. In this paper, we make analysis of the effects of aerobics on female university students' physical health.

\section{CURRENT STATE OF UNIVERSITY AEROBICS TEACHING}

\section{Body Teaching}

There are two kinds of body-static and dynamic, which mainly including arms, eyes, trunk, head and other parts' external expression in cardinal points during movement process. No matter folding or extending, grace or rough, there shows straight and elegant body during instantaneous static or flowing shift from beginning to end, giving people visual directness and emotional appeal (Zhang \& Peng, 2017). Body training is mainly cultivating students' correct and elegant movement and postures through some basic exercises of ballet; it is able to train students' coordinate ability in all body parts, rhythm sensation of movement and flexibility of joints through typical dancing and combined exercises, to improve students' body controllability, artistic expressive force and aesthetic consciousness.

The body teaching mainly covers bar exercises as training lower limbs and trunk strength, flexibility, skillfulness and coordination, enhancing control on the center of body and promoting balance ability effectively, and meanwhile standardizing students' body and posture, especially shaping the posture in leg. Basic part exercises-oriental exercises of various physical parts, such as swinging and circling of arms, circling of trunk, flexion and wave exercises. Grouping exercises, which is to compile a section of small groups with exercises in several single parts (Zhou et al., 2016). Ground grouping exercises, which are also low posture exercises, such as sitting( rectangular sitting, split sitting, kneel sitting, cross-legged sitting), lying(rear lying, front lying, lateral lying), supporting( rear supporting, front supporting, lateral supporting, ground supporting).We can even show our healthy and beautiful body through certain physical training.

\section{Dance Teaching and Training}

Implementation of dance teaching and training mainly aims to improve students' coordination and flexibility in body as well as grasping the rhythm, enhance students' physical quality, reinforce plasticity in body, enable students to control their body and extend limbs more freely, which is beneficial to student's expression of physical movement. At the same time, we should follow the principle of progressive and from simple to difficult when training to guarantee for efficiency during aerobics teaching. Generally, aerobics teaching adopts modern dance, jazz, Latin dance and folk dance in sports dance etc. (Zhang \& QIN, 2012). As an art, dance generally brings beauty enjoyment to people, students should pay attention to personal body shape when taking dance training, and they should be chest out and abdomen in, tending an overall upward body. Only straight beauty is realized in body, rhythmic beauty of dance movements can be presented during the dance process, and dancers' understanding on movement can be integrated in limbs' coordinated movement and audience emotions can be mobilized. The key points that we should pay attention to during teaching and training process are pushing the whole with the part of body, unremittingly exercising. By doing so, dance training could then be fulfilled. 


\section{Characteristics of Aerobics Body Teaching}

\section{Elegant and artistic}

Aerobics is artistic and elegant. In the process of training, student usually fulfills training and exercises of aerobics through elegant and slow movement, followed by the rhythm and transferred emotions and context in music. The elegance and artistry are shown in the process. Body training covers cultivation of people's spirit, temperament and style. People would form into a kind of elegant temperament gradually by grasping statistic, energy and spirit as required in training. Beauty body, decent appearance and polished manners may exert a larger impact on people's inner world; contribute to exercisers' elegant temperament. The elegant temperament is a closely combination of external form and spiritual world. As Confucian thinks, people's inner spiritual state is shown through external body, whereas beauty of character and spirit should be more a unified beauty of inner spirits an external body than only beauty of moral sentiments. No doubt, body training is a magic key to correct unhealthy body and shape elegant shape and temperament.

\section{Comprehensive and targeted}

Aerobics is a kind of general and dynamic aerobic sports with a combination of walking, running and jumping movements, which may develop whole bodies' joints and muscles fully and balanced. Aerobics teaching may mobilize exerciser's entire muscle during training process, enable their muscles to be better relaxed and exercised, remove excessive fat and effectively extend muscle and ligament of body. This may better improve female university students' uncomely body and physiological defects. In particular, it is conductive to correct Xtype legs.

\section{Diversified teaching contents}

There are various aerobics movements, including all kinds of basic movements in gymnastics and numerous movements from dances and martial arts. Among them, body exercise is conductive to correct body shape, chest out and waist erect, extend muscle and ligament, making human body slim and tall, letting appearance and body more beautiful and elegant. Meanwhile it exerts an impact on the changes of temperament in female university students. In aerobics teaching and training, ballet, dance and contents from gymnastics are generally adopted, which has rich movement contents, greatly arouse students' interests in learning aerobics, and enhance their positivity in learning aerobics. In addition, most of the aerobics movements are simpler, and it reduces difficulties and lower barrier of students' aerobics learning, enabling students to learn the event.

\section{ROLES OF AEROBICS TEACHING}

\section{Roles of Aerobics' Body Teaching}

In aerobics teaching, increase body exercises properly may improve students' positivity in learning such event. Teachers could timely correct some students uncoordinated movements in class promote their learning exercises and make classroom come alive through body teaching. There is uneven students' physical quality in university, so most of them do not know how to fully show their body beauty. When taking aerobics exercising, students could not comprehend deeply various techniques that an exerciser should pay attention to during exercises, and so their movement could not reach the standard, making them passive. Body exercises, however, are simple and graceful; students are easier to grasp sense and strength of movement when exercising. Therefore, they are easier to reach movement requirement. Furthermore, with the combination of students' favorite fashionable elements, doing exercises accompanied by music, which conforms to interest and habits of contemporary students, additional body exercises in aerobics class targeted at students' poor situation of uncoordinated and imitation ability, not only can make classroom come alive but also enhance students' passion for learning. On a whole, university students are weak, which mainly because they lack of corresponding physical exercises, and female university students, in particular. As elective course in university, aerobics provide a well platform for female 
students exercising. As aerobics movement is elegant, easier to access as well as rich in contents, while also is conductive to remove excessive fat, prevent from obesity, shaping perfect figure through aerobics teaching, it greatly arouses students' interests in learning aerobics to a great level.

\section{Roles of Aerobics Dance Teaching}

Dance training is helpful for improving students' coordination, flexibility and sense of rhythm. During dance, there would be strict and meticulous demands on movement of legs, increase proper dance movement exercises in aerobics training could therefore enrich students' comprehending on rhythm and movement, contribute to their sensation of perfect integration of movement and music. This is helpful for students' better presenting rhythm beauty of performing aerobics. Dance training can relax students' limbs; contribute to improvement of student's expression in body movement, better present movement. Aerobics learning and exercising could enhance physique, promote aesthetic ability and motivate characters. The increasing body beauty would make them more confident so that enable them to correctly examine their pros and cons, show their strong points and hide their weakness. Dance training in aerobics could greatly promote students' creativity, imagination and expression, and make great contributions to promotion of students' comprehensive quality.

\section{RESEARCH OBJECTS AND METHODS}

\section{Research Objects}

Select 10 female students from students taking aerobics as elective course in graduate 2014 to 2016 of this institute randomly, from which no obvious differences exists in their age, height and weight. All of them are in good physical quality without experience of taking special aerobics class.

\section{Research Method}

\section{Literature review}

Sort out relevant materials and documentary by searching aerobics teaching, body shape function via relative books, literature, CNKI and Wanfang Data.

\section{Experimental method}

In this study, vertical comparison is made on 10 female university students' body shape function changes before and after specialized aerobics training. They did not receive aerobics education, and will not take sports dance training after aerobics training.

\section{Body shape test}

Test items: chest circumference, waist circumference, hip circumference, thigh circumference, biceps circumference, subcutaneous fat in abdominal muscle, lumbar muscle and scapulae muscle

chest circumference, waist circumference, hip circumference, thigh circumference, biceps circumference;

\section{Test instrument: tape}

Test flow: Take test of chest circumference as an example, firstly, subject takes off clothes, stand at ease, put feet together, face right ahead and slowly lift lower jaw. Circle the tape on the chest (prominent point) horizontally from loose to tight.

subcutaneous fat in abdominal muscle, lumbar muscle and scapulae muscle 


\section{Test instrument: skin thickness tester}

Test flow: Measurer holds skin and subcutaneous fat in measured parts with thumb and index finger of left hand (alternatively, other four fingers) as wrinkle, makes skinfold parallel to long axis of body, while right hand takes skin thickness tester to measure thickness at the root of skinfold. Then, he relaxes skinfold that slightly holds and hold it again to measure. He would measure for three times successively and take the mean. Pressure in skin should be moderate when measuring, neither too big nor too small.

Body function conditions test

Test items: heart rate, breath, lung capacity, systolic pressure, diastolic pressure

\section{Resting heart rate}

Test instrument: stopwatch

Test flow: The subject sits in the testing positing silently, puts forearm of right arm on the table flatly, put the center of palm upward. Tester sit in the right of subject, press his pulse and measure. Record-use time/min as unit.

\section{Lung capacity}

Test instrument: vital lung capacity instrument, blowing nozzle and nasal splint

Test flow: When testing, subject sits next to instrument, understands and masters test flow, keeps blowing nozzle in mouth and tight it with nasal splint.

\section{Systolic pressure and diastolic pressure}

Test instrument: Pressure meter

Test flow: Subject sits down and rests for a while, gets arm through armlet and binds, and then measure the pressure with the arm exposed. The center of armlet is at the same height of heart, keeping a distance of 1 to 2 $\mathrm{cm}$ from the elbow joint. Press user's key and start measurement automatically. When measuring, subject should relax palm, put palm onward and be relaxed. The subject is not allowed to speak or move during measurement, read the data after measuring.

\section{PROCESS AND DISCUSSION}

\section{The Effects of Aerobics Teaching on Female University Students' Body Shape Aerobics teaching can correct uncomely body shape of female university students}

Body shape is external expression of human structure; there are different measurement standards on body shape in various periods and social backgrounds. By far, some female university students dare not correctly confront with personal physical growth. They tend to bow upper part and lower head when walking. Uncomely body shape mainly represents as special figure( too fat or too thin) and abnormal physical posture( chest backward, humpbacked, shrug, " $\mathrm{X}^{\prime \prime}$-type legs, “O”-type legs, toe-in and toe-out etc.). Facts prove that these uncomely physical postures can be refined and corrected to shift them toward beautiful by scientific and targeted body shape correction training. Aerobics teaching requires coordination and cooperation of hands, legs and foot as well as other parts. Exercisers may correct personal uncomely body shape through aerobics teaching. It achieves efficiency of tightening muscle, consuming excessive fat and finally realizes body correction and develops into correct body through movement training in head, neck, chest, shoulder and legs as well as coordinated cooperation training in whole body's movement. Good body posture is an important factor to form a people's temperament and form. Taking body exercise for a long time is helpful for even and harmonious development in muscle, bone and joint, 
Dong et al. / Effects on Female University Students' Physical Health

Table 1. 10 female university students body shape before and after training $(N=10)$

\begin{tabular}{|c|c|c|c|c|c|c|c|c|}
\hline $\begin{array}{l}\text { Female c } \\
\text { students }\end{array}$ & $\begin{array}{l}\text { Chest } \\
\text { umfere } \\
\text { Front } \\
\text { Rear }\end{array}$ & $\begin{array}{l}\text { Waist } \\
\text { umfere } \\
\text { Front } \\
\text { Rear }\end{array}$ & $\begin{array}{l}\text { Hip } \\
\text { umfere } \\
\text { Front } \\
\text { Rear }\end{array}$ & $\begin{array}{l}\text { Thigh } \\
\text { umfere } \\
\text { Front } \\
\text { Rear }\end{array}$ & $\begin{array}{c}\text { Biceps } \\
\text { cumfere } \\
\text { Front } \\
\text { Rear }\end{array}$ & $\begin{array}{l}\text { Abdominal } \\
\text { muscle } \\
\text { (subcutaneous } \\
\text { fat) } \mathrm{mm} \\
\text { Front } \\
\text { Rear } \\
\end{array}$ & $\begin{array}{c}\text { Lumbar muscle } \\
\text { (subcutaneous fat) } \\
\text { mm } \\
\text { Front } \\
\text { Rear }\end{array}$ & $\begin{array}{c}\text { Scapulae muscle } \\
\text { (subcutaneous fat) } \\
\text { mm } \\
\text { Front } \\
\text { Rear }\end{array}$ \\
\hline \multirow{2}{*}{1} & 84.40 & 68.07 & 87.82 & 52.19 & 22.03 & 16.87 & 12.50 & 11.30 \\
\hline & 84.42 & 66.05 & 86.91 & 51.90 & 22.01 & 16.84 & 9.53 & 9.63 \\
\hline \multirow{2}{*}{2} & 81.71 & 68.33 & 86.18 & 50.58 & 21.90 & 17.38 & 14.72 & 11.28 \\
\hline & 81.72 & 65.27 & 85.26 & 50.36 & 21.89 & 17.03 & 11.80 & 9.87 \\
\hline \multirow{2}{*}{3} & 87.55 & 68.16 & 87.82 & 51.55 & 22.87 & 16.90 & 12.57 & 11.37 \\
\hline & 87.56 & 64.88 & 86.87 & 51.29 & 22.85 & 16.87 & 9.51 & 9.98 \\
\hline \multirow{2}{*}{4} & 88.70 & 68.47 & 90.00 & 52.83 & 23.67 & 17.88 & 15.87 & 11.54 \\
\hline & 88.71 & 65.46 & 89.04 & 52.62 & 23.66 & 17.42 & 12.79 & 10.08 \\
\hline \multirow{2}{*}{5} & 85.34 & 68.55 & 89.45 & 53.80 & 22.88 & 17.94 & 16.34 & 12.27 \\
\hline & 85.35 & 65.22 & 88.54 & 52.94 & 22.87 & 17.56 & 13.25 & 10.61 \\
\hline \multirow{2}{*}{6} & 84.08 & 68.57 & 90.04 & 53.19 & 22.34 & 18.02 & 16.90 & 12.30 \\
\hline & 84.10 & 65.41 & 89.06 & 52.88 & 22.32 & 17.53 & 13.87 & 10.55 \\
\hline \multirow{2}{*}{7} & 84.17 & 68.27 & 88.09 & 50.30 & 23.30 & 17.34 & 13.11 & 11.48 \\
\hline & 84.18 & 65.02 & 87.16 & 50.24 & 23.28 & 17.28 & 10.20 & 9.74 \\
\hline \multirow{2}{*}{8} & 88.85 & 68.61 & 91.02 & 54.15 & 23.34 & 18.30 & 17.05 & 12.32 \\
\hline & 88.87 & 65.35 & 90.09 & 52.54 & 23.33 & 18.01 & 13.96 & 10.61 \\
\hline \multirow{2}{*}{9} & 92.85 & 68.82 & 93.36 & 54.39 & 24.02 & 18.53 & 17.08 & 12.34 \\
\hline & 92.87 & 65.54 & 92.39 & 53.87 & 24.01 & 18.02 & 13.98 & 10.06 \\
\hline 10 & 87.08 & 68.37 & 88.36 & 51.87 & 23.47 & 17.84 & 15.23 & 12.18 \\
\hline \multirow{2}{*}{ Mean } & 87.09 & 65.16 & 87.45 & 51.54 & 23.45 & 17.49 & 12.30 & 10.44 \\
\hline & 86.47 & 68.42 & 89.21 & 52.48 & 22.98 & 17.70 & 15.13 & 11.83 \\
\hline \multirow{2}{*}{$\begin{array}{c}\text { Standard } \\
\text { values }\end{array}$} & 87.48 & 65.33 & 88.27 & 52.01 & 22.96 & 17.40 & 12.11 & 10.15 \\
\hline & 90.31 & 63.75 & 91.64 & 53.79 & 23.2 & $12-20$ & $12-16$ & $10.4-12.4$ \\
\hline
\end{tabular}

refining uncomely body vigorously, forming elegant physique and further showing a good temperament and accomplishment in daily life, impressing people as vigorous, healthy and progressive. There is no medicine to cure uncomely body such as humpback in clinical, which could only be corrected through exercise therapy. In the exercise therapy, it exerts curative effects on erecting spine mainly through exercising spine and strengthening muscular strength of weak parts. As shown in Table 1, 10 female university students' mean scapula muscle sebum changed from 11.83 before professional aerobics exercises to 10/15 after such exercise. All were in normal scope. Subcutaneous fat in scapula muscle, however, decreases after exercising, showing a negative growth trend. The fat decreased obviously. The reduction can refine figure, strengthen muscle strength, and exercise joints in all body parts of students as well as develop muscle in a balanced way. Through aerobics training, subcutaneous fat could be consumed in various parts so that muscular strength could be enhanced. By regular aerobics teaching, uncomely bone could be developed towards correct direction by the impacts of pressure and tension so that realize uncomely figure correction.

\section{Contribute to beautiful female university students' body shaping}

All parts' muscle of female university students in sports major could be developed coordinated through elegant body exercises and event strength training. Meanwhile, coordination and sensitivity in their overall trank could be strengthened that makes up for drawbacks in their body and optimizes their form. Body training is a kind of fitness event. In training process, various movements such as walking, running and jumping could make a more beautiful figure for exercisers. At the same time, everyone can express inner feeling through personal body language. Therefore, it possesses exercise value of aerobics but also graceful characteristic of dance, from which athletes fully feel beauty and perform themselves accomplished by elegant music, which is very helpful for cultivating athletes' expression in movement. Research shows that female university students' rear hip circumference was reduced after exercises, suggesting such a aerobic fitness event as aerobics has a good exercising efficiency in improving fat female university students' external form. There are rich and varied aerobics 
Table 2. 10 female students' body shape changes before and after training $(\mathrm{N}=10)$

\begin{tabular}{|c|c|c|c|c|c|c|c|c|}
\hline $\begin{array}{l}\text { Female } \\
\text { students }\end{array}$ & $\begin{array}{c}\text { Chest } \\
\text { circumference }\end{array}$ & $\begin{array}{c}\text { Waist } \\
\text { circumference }\end{array}$ & $\begin{array}{c}\text { Hip } \\
\text { circumference }\end{array}$ & $\begin{array}{c}\text { Thigh } \\
\text { circumference }\end{array}$ & $\begin{array}{c}\text { Biceps } \\
\text { circumference }\end{array}$ & $\begin{array}{c}\text { Abdominal } \\
\text { muscle } \\
\text { (subcutaneous } \\
\text { fat) }\end{array}$ & $\begin{array}{c}\text { Lumbar } \\
\text { muscle } \\
\text { (subcutaneous } \\
\text { fat) }\end{array}$ & $\begin{array}{c}\text { Scapulae } \\
\text { muscle } \\
\text { (subcutaneous } \\
\text { fat) }\end{array}$ \\
\hline 1 & +0.02 & -1.57 & -0.91 & -0.29 & -0.02 & -0.03 & -2.97 & -1.67 \\
\hline 2 & +0.01 & -3.06 & -0.92 & -0.22 & -0.01 & -0.35 & -2.92 & -1.41 \\
\hline 3 & +0.01 & -3.28 & -0.95 & -0.26 & -0.02 & -0.03 & -3.06 & -1.39 \\
\hline 4 & +0.01 & -3.03 & -0.96 & -0.21 & -0.01 & -0.46 & -3.08 & -1.46 \\
\hline 5 & +001 & -3.33 & -0.91 & -0.86 & -0.01 & -0.38 & -3.09 & -1.66 \\
\hline 6 & +0.01 & -3.16 & -0.98 & -0.31 & -0.01 & -0.49 & -3.03 & -1.75 \\
\hline 7 & +0.01 & -3.25 & -0.93 & -0.06 & -0.02 & -0.06 & -2.91 & -1.74 \\
\hline 8 & +0.01 & -3.26 & -0.93 & -1.61 & -0.01 & -0.29 & -3.09 & -1.71 \\
\hline 9 & +0.02 & -3.28 & -0.97 & -0.52 & -0.01 & -0.51 & -3.1 & -2.28 \\
\hline 10 & +0.01 & -3.21 & -0.91 & 0.33 & -0.01 & -0.35 & -2.93 & -1.74 \\
\hline
\end{tabular}

movements, which not only integrates diversified basic movements in gymnastics, but also combines with various movements in martial arts, and possesses diversity in shaping body.

Aerobics body training is conductive to female university students in sports major to chest out and waist erection, correct body form, extend muscle and ligament, making human body slim and tall and appearance and body more decorous. Research results show that there occurred changes in body shape of 10 female university students after targeted fitness exercising to a different level. For instance, as shown in Table 1, 10 female university students have significant differences in circumferences of front and rear waist, legs and hips before and after training. Compared to standard value, mean of waist, legs and hip after training gets closer to such value. Table 2 suggests that waist circumference, thigh circumference and biceps circumference show a negative growth trend after training. In the view of individual variable, all previous obesity and slim female students, have relative significant changes compared to others. This suggests that muscle strength is obviously enhanced, muscular fiber becomes rough and physique tends to more robust after systematic training. Hip circumference becomes even complete and gluteal line has somewhat upgraded. Besides, various chest movement exercises at ordinary times enriches chest and makes it high resilience, and then contributes to beautiful body shaping for female university students. There are varieties of exercising ways in entire aerobics exercise and widely exercise parts, as head, neck, shoulder, hip, chest, abdomen, waist, hip, thigh and shank, all have their own exercising ways.

Among them, flexibility exercises and basic body posture training are helpful for female university students in sports major to correct body form-chest out and waist erect. Various wave twisting and other movement is helpful for developing waist and abdominal and lumbar muscle, facilitating vigorousness and flexibility of waist and abdomen, and so sets curve of beauty body off. The kicking movement and hip movement in all directions build hip muscle strong and somewhat lifting, making people feel the enhancement of center and beautiful legs. Chest is an important manifestation of beauty body, various chest expanding and body extension exercises could make chest muscled and increase the volume of thoracic cavity. Thus, female university students in sports major could show their busty and resilient beautiful body form.

\section{Contribute to remove excessive fat from female university students}

As material civilization improves, there emerge civilized diseases such as obesity and hypertension. As all known, aerobic exercises are the best methods for losing weight, from which most effective ones are beautybuilding and body-building exercises that exerts effects by metabolism way in low impact and high energy. After aerobics training, female university students in sports major could get burn their excessive fat and nutrient. This may prevent them against putting on weight and also improve their immunity, facilitate blood circulation and guarantee for physical health.

Table 1 indicators suggest that aerobics exert different impacts on various body parts, though its exercise duration is longer and participated parts of people are quite a lot. There are usually three parts composed of aerobics, part one is activity in each joint, which is mainly movement as extending and pulling; part two is ground 
exercises, which is mainly exercises in abdomen and waist; part three is jumping exercises, which is mainly lower limbs exercises. We receive response from subjects and learn that most of them feel the exercise amount in waist, abdomen and lower limbs are larger, while those in upper limbs activities are smaller by comparing with them. Therefore, changes in circumference are larger. Relative research shows that our body water and fat would be consumed after taking physical exercises and then tended to be stable. However, there would emerge weight gain in regular sports exerciser after exercising in cycle, suggesting growth of muscle is a feature in such group of people. So, keeping a scientific aerobics exercises for a long time has a certain impact on controlling the weight.

Relatively, having entered into university, female students basically halted training with a great reduction in amount of exercises, their weight were therefore rebound to a certain degree, representing an increase in subcutaneous fat in waist, abdomen and thigh. Taking aerobics exercising could just prevent this from happening. In accordance with fat metabolism's exercise physiology, fatty acid generated by fat metabolism could be greatly burnt in skeletal muscle that finally contributes to fat reduction.

In Table 2, having received one term's aerobics teaching, the ten female university students' subcutaneous fat in lumbar muscle, abdominal muscle and scapulae muscle tended to negative growth. From the perspective of circumference changes, index of chest circumference, waist circumference, thigh circumference and shank circumference after exercising were obviously lower than those before exercising. That is because body's fat utilization improves comparing to sugar utilization after taking regular aerobic exercises. Thus, we could fight against metabolic disorders of fat through reduction body fat. Moreover, after exercising, both oxidation of fatty acid in body lactic acid and glycogen reserve that consumed would consume energy.

In addition, endocrine changes and temperature rising caused by exercises would make body metabolism at rest after exercising be higher than that before exercise and continue to one to two hours and even longer. Therefore, keeping aerobics exercises for a long time could reduce excessive body fat, strengthen our muscle strength, which plays a positive role in female university students in sports major to build beauty and lose weight so that shape themselves and keep a beauty figure.

\section{Effects of Aerobics Teaching on Body Function of Female University Students}

\section{Improve physiological function of female university students in sports major}

Body function refers to life activity displayed by entire human body as well as its systems and organs. The obviously improvement in heart and lung function is manifested by a reduced resting heart rate, obviously growing lung capacity. This suggests that aerobics play an obvious promotion to respiratory system and aerobic endurance. Table 3 shows that 10 subjects' resting heart rates are within normal scope before and after training. Table 4 indicates that a negative growth tendency occurs to such rates as obvious slower cardiac activity. At this time, it extends relaxation period of heart, has myocardium quite rested with enough blood. Additionally, after training, myoglobin contents would increase, heart nutrient will be strong, stroke volume will increase, oxygen utilization rate would be promoted and body would be economized. Thus, basic pulse becomes slower, and heart rate will slow down. From the perspective of breathe, 10 subjects' respiratory rate greatly decreases comparing to that before training, showing a negative growth trend, but lung capacity on the contrary obviously promotes, showing a positive growth trend. This shows that certain fitness exercises change functions of respiratory organs. Reasons for that are the enlarged thorax results in an increase in contraction strength and amplitude in respiratory muscle, and so there is an increase in lung capacity so that full supply of oxygen is ensured when exercising. In the view of blood pressure changes, there is an obvious increase in systolic pressure, showing a positive increase trend, while on the contrary an decrease in diastolic pressure, showing a negative growth trend. Both the increase and decrease values are within normal scopes, suggesting the implementation of systematic training has adjustment of central nervous system on cardiovascular system improved. This fully shows students have really reinforced their cardiovascular system by doing so. 
Table 3. 10 female university students' body function conditions before and after training $(N=10)$

\begin{tabular}{ccccccccccc}
\hline \multirow{2}{*}{ Female students } & \multicolumn{2}{c}{ Heart rate } & \multicolumn{2}{c}{ Breath } & \multicolumn{2}{c}{ Lung capacity } & \multicolumn{2}{c}{ Systolic pressure } & Diastolic pressure \\
& Front & Rear & Front & Rear & Front & Rear & Front & Rear & Front & Rear \\
\hline 1 & 78.70 & 72.90 & 18.50 & 16.10 & 2680 & 2784 & 108.3 & 112.3 & 81.3 & 76.4 \\
\hline 2 & 88.70 & 82.60 & 24.70 & 22.45 & 3487 & 3420 & 127.7 & 128.6 & 89.5 & 84.5 \\
\hline 3 & 70.30 & 64.70 & 16.90 & 14.80 & 2433 & 2539 & 103.1 & 107.5 & 75.4 & 71.2 \\
\hline 4 & 88.43 & 80.83 & 23.10 & 20.80 & 3315 & 3319 & 125.3 & 127.8 & 88.1 & 83.0 \\
\hline 5 & 68.38 & 63.94 & 12.30 & 10.85 & 1876 & 1987 & 102.3 & 105.8 & 71.4 & 66.4 \\
\hline 6 & 86.42 & 79.82 & 22.70 & 21.10 & 3016 & 3121 & 120.4 & 123.9 & 86.9 & 81.4 \\
\hline 7 & 86.15 & 79.55 & 20.90 & 18.40 & 2934 & 3043 & 119.7 & 123.2 & 86.7 & 80.9 \\
\hline 8 & 72.86 & 68.26 & 17.30 & 15.30 & 2586 & 2682 & 105.2 & 109.6 & 78.7 & 73.7 \\
\hline 9 & 78.81 & 73.21 & 20.50 & 17.90 & 2721 & 2925 & 110.9 & 115.3 & 85.9 & 80.1 \\
\hline 10 & 69.45 & 64.30 & 16.10 & 13.70 & 2410 & 2516 & 103 & 106.1 & 74.2 & 70.2 \\
\hline Mean & 78.82 & 73.01 & 19.3 & 17.14 & 2745 & 2833 & 112.5 & 116.0 & 81.8 & 76.7 \\
\hline Standard value & 70 & 90 & 16 & 20 & 2500 & 3500 & 90 & 130 & 60 \\
\hline
\end{tabular}

Table 4. 10 female students' body function changing conditions before and after training $(\mathrm{N}=10)$

\begin{tabular}{|c|c|c|c|c|c|}
\hline Female students & Heart rate & Breath & Lung capacity & Systolic pressure & Diastolic pressure \\
\hline 1 & -5.8 & -2.4 & +104 & +4 & -4.9 \\
\hline 2 & -6.12 & -2.25 & +136 & +2.9 & -5 \\
\hline 3 & -5.6 & -2.1 & +106 & +4.4 & -4.2 \\
\hline 4 & -7.6 & -2.3 & +104 & +4.5 & -5.1 \\
\hline 5 & -4.44 & -1.8 & +111 & +3.5 & -5 \\
\hline 6 & -6.6 & -1.6 & +105 & +3.5 & -5.5 \\
\hline 7 & -6.6 & -2.5 & +109 & +3.5 & -5.8 \\
\hline 8 & -4.6 & -2 & +96 & +4.4 & -5 \\
\hline 9 & -5.6 & -2.6 & +204 & +4.4 & -5.8 \\
\hline 10 & -5.15 & -2.4 & +106 & +3.1 & -4 \\
\hline
\end{tabular}

Female university students in sports major that taking aerobics exercises have increased their lung capacity and decreased resting heart rate. This suggests that implementation of aerobics exercises plays a positive role in promotion to physiological function of the students.

\section{Promote heart and lung function of female university students in sports major}

Table 3 indicates that 10 female university students' lung capacity has obviously increased after training, showing an increasing tendency. The mean changes from 2745 before training to 2833 after training within the scope of standard value. Additionally, Table 4 shows that lung capacity tends to increase positively before and after training, suggests that female university students have improved their heart and lung function after training for a term. In aerobics, public aerobics are aerobic exercises, respiratory muscle improves when exercising. When breathing in, Chest can be fully extended, more pulmonary alveoli expands and more oxygen can be taken in ; when breathing out, contraction of thorax should be maximized so that more carbon dioxide waste could be removed. Through long-term aerobics exercising, people would get deeper breath, and breath times would be shortened. This is a most beneficial way to gain maximum breath, having respiratory muscle fully rested. Good respiratory function suggests strong working capacity of lung. And meanwhile, by doing so, lung resilience and respiratory muscle could be exercised, thorax therefore could grow better, and heart and lung functions could be improved. Specifically, by aerobics exercising, resting heart rate slows down, and lung capacity obviously rises. After training, resting heart rate decreases comparing to that before exercising, suggesting heart and lung's stroke volume increases after regular exercises. When resting, a low heart rate could satisfy the demands on body metabolism. Blood pressure's reduction is a sign of good changes in heart and lung functions, which may be related to the increase in tensity of Nervi vagus after exercising. 


\section{Strengthen cardiovascular function of female university students}

As other tissues, cardiac muscle may strengthen its contractility, improve circulation condition of coronary artery and increase blood capillary and get fully nutrient supply by long-term moderate exercising. Table 3 and 4 indicates that after aerobics exercising, 10 female university students' diastolic pressure reduces, showing a negative growth trend comparing to that before training. This indicates their heart relaxation period gets prolonged that provides longer rest time for myocardium and offers it plenty of blood. In the aspect of respiratory frequency, it slows down, showing a negative growth tendency. However, lung capacity promotes, showing a growth trend. This fully suggests that aerobics teaching can promote cardiovascular system of female university students in sports major remarkably, so that offers them plenty of oxygen during exercise process.

\section{CONCLUSIONS AND SUGGESTIONS}

\section{Conclusions}

i) Aerobics teaching and training is conductive to correct female students' uncomely body form, promote uncomely bone shapes developed toward correct direction under pressure and tension, and further correct uncomely body.

ii) Aerobics teaching and training is conductive to shaping of beautiful female students' body. It strengthens whole body's coordination and sensitivity, and optimizes our body.

iii) Aerobics teaching and training may reduce excessive fat of female university students. Through aerobics training, their excessive fat is burnt, which not only avoid obesity but also promotes physical immunity, facilitates blood circulation and ensures physical health.

iv) Aerobics teaching and training could improve physiological functions of female university students. Certain fitness exercises could increase contraction ability and amplitude of respiratory muscle, improving central nervous system's adjustment on cardiovascular system and so the female university students' physiological functions.

v) Aerobics teaching and training could promote respiratory function of female university students. Implementing aerobics exercises could have lung resilience and respiratory muscle exercised, and so contributes to better growth of thorax and better improve heart and lung capacity.

vi) Aerobics teaching and training could promote female university students' cardiovascular system. It is able to obviously promote their cardiovascular system so that offers sufficient oxygen during exercising process.

\section{Suggestions}

i) In aerobics teaching, female university students are not only required to correct uncomely postures with teachers' guidance in class, they should also practice after class. Exercising only in classroom is not enough; they should remain personal posture at daily life.

ii) Aerobics teaching does not accomplish in an action, similarly, beauty body shaping could be easily realized. When teaching aerobics, we should carry out systematically, and had better utilize some instrument to improve our body and promote our temperament.

iii) There are three kinds of aerobics teaching, such as aerobic, public and competitive ones. The female university students that just take specialized training should take more aerobics training when sharping body, which is of great help.

iv) It suggests that female university students should spend some time in physical exercising when concentrating on cultural course learning, and aerobics is an ideal sports event. 
v) It is able to learn from advantages in female university students' participating in aerobics teaching, popularize general aerobics course in school, and select aerobics course conform to physiological and psychological characteristics of them. Besides, it should also active develop the second class to attract the students to take regular and lasting exercises as well as encourage male university students to join in aerobics exercises. This would build a foundation for lifelong sports.

\section{REFERENCES}

Chen, C., \& Zhang, B. (2016). Factor analysis in optimizing the structure of the sports industry. In Z. Henan and J. Y. Beijing (eds.) 2016 National Convention on Sports Science of China, Zhengzhou China, SEP 23-25 2016. France: EDP Sciences. doi:10.1051/ncssc/201701013

Li, X. P., Xu, M. H., Zhao, F. N., Zhang, L., \& Zhang, G. Z. (2017). Research on the Construction of Ecological System of Internet Learning Resources for Postgraduates. Academic Degrees E Graduate Education, (4), 26-30. doi:10.16750/j.adge.2017.04.006

Zhang, B., \& Peng, P. (2017). Research on the Development of Education Resources for the Internet Plus Universities in the National Health Field. Eurasia Journal of Mathematics Science and Technology Education, 13(8), 50855093. doi:10.12973/eurasia.2017.00984a

Zhang, B., \& Qin, X. P. (2012). “Use money to buy service”: new ideas for sports basic public service provision mechanism. Journal of Shandong Institute of Physical Education and Sports, 28(5), 6-10. doi:10.3969/j.issn.10062076.2012.05.002

Zhou, J. S., Fang, Q., \& Zhang, J. H. (2016). Evolution and Trend of China Aerobics Competition. Journal of Beijing Sport University, 39(4), 132-140.

\section{http://www.ejmste.com}

